\title{
A study of drinking behavior among undergraduate students in Chonburi
}

\author{
Pornrapee Torsak \& Waiphot Kulachai \\ Burapha University, Chonburi, Thailand
}

\begin{abstract}
The objectives of this research were to study drinking behavior of undergraduate students in Chonburi, and to examine factors affecting drinking behavior of the students. The respondents were 397 undergraduate students of three Thailand universities, namely Burapha University, Rajamangala University of Technology Tawan-ok, and Kasetsart University Sriracha Campus. The authors employed questionnaire as a research tool to collect the primary data which were analyzed using stepwise regression analysis. The findings indicated that poor family relationship and media influence had positive effect on drinking behavior of undergraduate students. However, friend influence, accessibility to alcohol shop, attitude toward drinking, and stress had no influence on drinking behavior of undergraduate students. Findings and implication then were discussed.
\end{abstract}

Keywords: drinking behavior, factors leading drinking behavior, family relationships

\section{INTRODUCTION}

Nowadays, Thai people drinking behavior has been increasing not only among adult but also among teenagers. The World Health Organization (WHO, 2014) reported that, during 2003-2005, Thai people consumed around 6.8 liters annually. The consumption rate increased to 7.1 liters during 2008-2010. The most popular alcohol drink among Thai people was liquor, beer, and wine respectively.

Drinking alcohol among teenagers could result in aggression and social disorder (Sornpaisarn et al. 2006). It also leads to inappropriate behaviors, such as skipping classes, poor academic performance, conflicts with parents, fighting, stealing, and aggressive driving. Furthermore, it has negative consequences on personal health; like high blood pressure, liver cirrhosis, gastritis, brain disorder, behavioral disorder, and intelligence disorder. A number of injuries and deaths are also associated with alcohol drinking (Ministry of Public Health 2005).

There are various factors leading to drinking behavior. Relationship in the family is one of the most important factors that affect drinking behavior of teenagers (Chuenkhum 1999). A study by Vanassche et al. (2014) found that parental conflict resulted in alcohol use among teenagers. Students who were not satisfied with parental relationship tend to have heavy use of alcohol and other substances (Ledoux et al. 2002). Hence, the first hypothesis was established as follows:

H1: Poor family relationship has positive relationship on drinking behavior

Some studies found a positive relationship between friend influence and drinking behavior among young people (Bot et al. 2005, Zhang et al. 2012, Previte et al. 2015). These indicated that young people, especially university students are attached to friend and peer group. They are less monitored by their parents so they could be influenced by their friends to practice drinking. The second hypothesis then was proposed as follows:

$H 2$ : Friend influence has a positive relationship on drinking behavior

Media channel today's allows young people to get information about various kinds of beverage and alcohol drinks. The advertisement through various media channels does have an influence on one's decision making on alcohol use. This was supported by previous studies which found positive relationship between media influence and drinking behavior among young people (Mapulane, 2014; Moreno et al. 2016). The third hypothesis was proposed as follows: 
H3: Media influence has a positive relationship on drinking behavior

Easy access to alcohol is quite important and leads to alcohol drinking practice among young people. If alcohol shops or café are located close to one's residence, he or she might get access to alcohol easily. This could encourage and facilitate young people to practice drinking. Previous studies found that accessibility to alcohol shops was associated with drinking behavior among adolescents (Halverson 2004, Lu et al. 2015). The fourth hypothesis, therefore, was proposed.

H4: Accessibility to alcohol shop has positive relationship on drinking behavior

There was a positive relationship between negative attitude toward drinking and drinking behavior according to previous studies (McCarty et al. 1983, Gaines, 2014). This implies that the higher young people perceive negative attitude towards the risk of alcohol consumption, the more likely the young people will perform or practice drinking. The fifth hypothesis then was proposed.

H5: Attitude towards drinking has positive relationship on drinking behavior

Some people practice drinking in order to socialize with friends. However, stressful young people may consume alcohol to relief it. Previous studies provide supportive findings for this statement (Hutchinson et al. 1998, Pauley \& Hesse 2009). Hence, we proposed the last hypothesis as follows:

H6: Stress has a positive relationship on drinking behavior

Based on the review of some literatures, the conceptual framework in this study was proposed as illustrated in Figure 1.

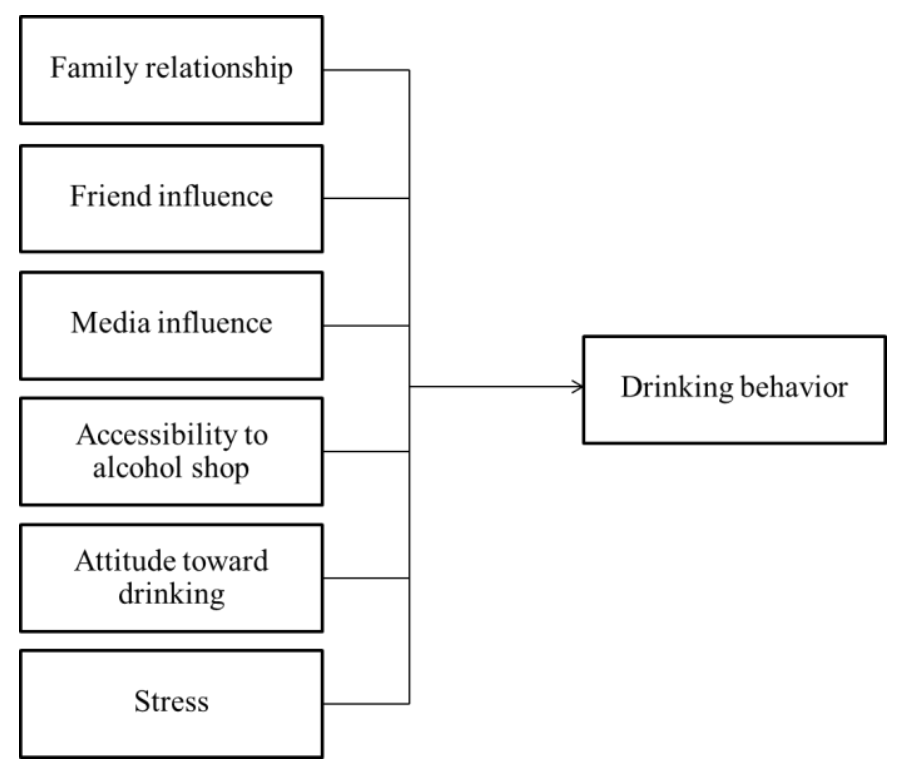

Figure 1. Conceptual framework

\section{METHOD}

\subsection{Sample}

The participants in this research were 397 undergraduate students from three Thailand universities namely Burapha University, Rajamangala University of Technology Tawan-ok, and Kasetsart University Sriracha Campus. The majority of the samples (58.4\%) were female. About $44.6 \%$ aged 20 and 21 years old. Around $34.3 \%$ got a financial support from their parents approximately THB 6,000 9,000/month. Most of them (59.4\%) have been living in dormitory or apartment. They reported that their fathers have been drinking. The most popular drink among undergraduate students was a beer that accounts for $42.6 \%$. They drank 1-2 times a week $(74.1 \%)$. The main reasons for drinking were socializing with friends $(33.8 \%)$ and coerced by friends $(30.7 \%)$. Most of them drank with friends $(85.4 \%)$ and took around 1-2 hours for each occasion (34.5\%). About 51.9\% spent less than THB 200 each occasion. Half of them $(50.1 \%)$ reported having increased expenses on alcohol and about $76.8 \%$ reported not having a health problem.

\subsection{Measures}

For all measures in this study, except demographic questions, participants indicated their levels of agreement with the items using a 5-point's Likert scale anchored by (1) strongly disagree and (5) strongly agree.

Drinking behavior was measured using the three items. This measurement revealed scores showing an alpha reliability of .91. Example items include "I always drink and it affects my academic performance", "I drink alcohol heavily so I cannot remember what has happened", and "I drink alcohol heavily so it leads to fighting with others."

Family relationship was measured using the six items. This measurement revealed scores showing an alpha reliability of .93. Example items include "My parents rarely have time with me", "I always have a problem and conflict with my parents", and "I have less commitment with my parents".

Friend influence was measured using the five items. This measurement revealed scores showing an alpha reliability of .91. Example items include "Most of my friends drink alcohol", "I would like to be accepted by my friends so I have to drink", and "My friends may not happy if I do not drink with them".

Media influence was measured using the five items. This measurement revealed scores showing an alpha reliability of .94. Example items include "Al- 
cohol advertisement encourages me to practice drinking", "The advertisement indicates that drinking alcohol may bring me more happiness", and "Advertisement on media channels allows me to get information about new and various kinds of alcohol products".

Accessibility to alcohol shop was measured using the three items. This measurement revealed scores showing an alpha reliability of .86. Example items include "There are some alcohol shops nearby my place so purchasing alcohol drink is very easy", "The alcohol shops are opened 24 hours", and "There are some night entertainments close to my place so accessing to alcohol is quite convenient".

Attitude towards drinking was measured using the five items. This measurement revealed scores showing an alpha reliability of .90. Example items include "Drinking alcohol could enhance bravery", "Drinking alcohol makes me feel like having higher social status", and "Drinking alcohol means I am more masculine".

Stress was measured using the five items. This measurement revealed scores showing an alpha reliability of .90. Example items include "Drinking alcohol could relieve my stress", "I drink when I have a conflict with my family members", and "I drink alcohol after work to release my exhaustion."

\subsection{Analysis}

The data were analyzed using stepwise regression analysis. This technique is suitable for getting a regression model which has the fewest number of statistically significant independent variables. This technique also provides maximum predictive accuracy according to Hair et al. (2014).

\section{RESULTS}

According to stepwise regression analysis technique, independent variables are added into the equation model one by one at each stage. It also requires a correlation between each independent variable and dependent variable. The effect of each independent variable on dependent variables is illustrated in Table 1. The partial correlations range from a high of .483 (FR) to a low of .140 (ST). Since family relationship (FR) was highly correlated with drinking behavior (DB), it should be the first variable entered, followed by Media Influence (MI), Accessibility to Alcohol Shop (AC), Friend Influence (FI), Attitude towards Drinking (AT), and stress (ST) in that order.
Table 1. Correlations matrix

\begin{tabular}{|c|c|c|c|c|c|c|c|}
\hline Variable & DB & FR & FI & MI & $\mathrm{AC}$ & $\mathrm{AT}$ & ST \\
\hline DB & - & & & & & & \\
\hline FR & $.483 * *$ & - & & & & & \\
\hline FI & $.222 * *$ & $.454^{* *}$ & - & & & & \\
\hline MI & $.269^{* *}$ & $.357 * *$ & $.401 * *$ & - & & & \\
\hline $\mathrm{AC}$ & $.245^{* *}$ & $.345^{* *}$ & $.388 * *$ & $.367 * *$ & - & & \\
\hline AT & $.193 * *$ & $.338 * *$ & $.620 * *$ & $.488^{* *}$ & $.395^{* *}$ & - & \\
\hline ST & $.140 * *$ & $.215^{* *}$ & $.432 * *$ & $.443 * *$ & $.390 * *$ & $.770 * *$ & - \\
\hline
\end{tabular}

$* *$ Sig. $<.01$

Table 2 Stepwise regression analysis results

\begin{tabular}{lccccc}
\hline Variable & $\mathrm{B}$ & $\begin{array}{l}\text { Std. } \\
\text { Error }\end{array}$ & $\beta$ & $\mathrm{t}$ & Sig. \\
\hline Conlnstant & .576 & .116 & & 4.945 & .000 \\
FR & .499 & .053 & .443 & 9.457 & $.000^{* *}$ \\
$\mathrm{MI}$ & .109 & .046 & .111 & 2.366 & $.018^{*}$ \\
\hline $\mathrm{R}=.494, \mathrm{R}^{2}=.244$, Std. Error $=.751, \mathrm{~F}=5.599$, Sig. $=.018$ \\
\hline
\end{tabular}

Table 2 shows that family relationship (FR) and media influence (MI) have contributed towards $\mathrm{R}^{2}$ value (adjusted $\mathrm{R}^{2}=0.244, \mathrm{~F}=5.599, p$-value $<0.05$ ). These two variables could explain $24.4 \%$ of the variation of drinking behavior. However, friend influence (FI), accessibility to alcohol shop, attitude toward drinking (AT), and stress had no relationship on drinking behavior among undergraduate students. The predictive equation would be written as follows:

$$
\mathrm{DB}=0.576+0.499 . \mathrm{FR}+0.109 . \mathrm{MI}
$$

The equation indicates that when the FR increases by 1 unit, the drinking behavior will increase by .499. Also, if the MI increases by 1 unit, the DB will increase by .109. This also shows that family relationship (FR) is the most important factor affecting drinking behavior (DB).

\section{DISCUSSION AND CONCLUSION}

The authors found that drinking behavior was influenced by family relationship and media influence. The strong relationship between family relationship and drinking behavior supported the results of previous studies (Chuenkhum, 1999; Ledoux et al. 2002; and Vanassche et al. 2014). This means that undergraduate students whose relationship with family are poor will likely to practice drinking compared to those who are not. Hence, attention is a very im- 
portant issue to cope with alcohol drinking among students. Parents should pay much attention to their activities. Building and creating family activities and spending more time with their children are critical to prevent them from using alcohol and other substances.

Media influence also had a positive relationship with drinking behavior among students. This supported the findings of previous studies (Mapulane, 2014 and Moreno et al. 2016). Related public and private organizations should concern more on the media contents. Restricted law enforcement against alcohol advertisement should be promoted. Also, policymakers should realize on alcohol drinking among students as a national issue. A clear policy to deal with this problem should be initiated since young people are the future of the country.

Friend influence had no relationship on drinking behavior among the students which was inconsistent with previous studies (Bot et al. 2005, Zhang et al. 2012, \& Previte et al. 2015). Accessibility to alcohol shop also had no influence on drinking behavior which did not support the findings of Halverson (2004) and Lu et al. (2015). We also found no relationship between attitude towards drinking and drinking behavior which was contrary to the previous studies (McCarty, 1983; Gaines, 2014). Finally, stress is not the influential factor in drinking behavior. This is not consistent with previous findings (Hutchinson et al. 1998, Pauley \& Hesse, 2009).

Based on the findings obtained from this study, parents and related stakeholders should be aware of building a good relationship with young people and encourage them to have extra activities. Hence, they will have less time exposing to alcohol and other risky behaviors. Restriction on media content and advertisement must be enforced. Furthermore, indepth study on this issue should be conducted in other universities in order to strengthen the body of knowledge of alcohol consumption among university students. Finally, countermeasures against heavy drinking behavior among students should be jointly set up by the university, pub owners, and the related public, private, and NGOs organizations.

\section{REFERENCES}

Bot, Sander .M., Rutger C.M.E. Engels, Ronald A. Knibbe, \& Wim H.J. Meeus. 2005. Friend's drinking behaviour and adolescent alcohol consumption: The moderating role of friendship characteristics. Addictive Behaviors 30: 929 947.

Chuenkhum, S. 1999. Drinking behavior among teenagers in Thai society. Unpublished master's thesis. Ramkhamhaeng University. Thailand.
Gaines, L. 2014. Student attitudes towards drinking behaviors. Unpublished master's thesis. University of New Hampshire. Durham.

Halverson, G. 2004. Impact of accessibility, perception of harm, and peer use on the use of marijuana and alcohol by rural-dwelling African-American adolescents. UW-L Journal of Undergraduate Research VII: 1-8.

Hutchinson, G. T., Patock-Peckham, J. A., Cheong, J., \& Nagoshi, C. T. 1998. Irrational beliefs and behavioral misregulation in the role of alcohol abuse among college students. Journal of Rational Emotive and Cognitive Behavior Therapy 16: 61-74.

Ledoux, S., Patrick Miller, Marie Choquet, \& Martin Plant. 2002. Family structure, parent-child relationships, and alcohol and other drug use among teenagers in France and the United Kingdom. Alcohol and Alcoholism 37(1): 52-60.

$\mathrm{Lu}$, S. Songming Du, Zhoupeng Ren, Jing Zhao,Christina Chambers, Jinfeng Wang, \& Guansheng Ma. 2015. Accessibility of catering service venues and adolescent drinking in Beijing, China. International Journal of Environmental Research and Public Health 12: 7208-7219.

Mapulane, M.G. 2014. Effects of televised alcohol advertisements on the drinking bahaviour of youth: A case study of Praktiseer community in Greater Tubatse Municipality. Unpublished master's thesis. University of Limpopo. Polokwane.

McCarty, D., S. Morrison, \& K.C. Mills. 1983. Attitudes, beliefs and alcohol use. An analysis of relationships. Journal of Studies on Alcohol 44(2): 328-341.

Ministry of Public Health. 2005. What is alcohol? Retrieved from https://eng.moph.go.th/public/ news/view.asp?id=964

Moreno, M.A., Jon D’Angelo, \& Jennifer Whitehill. 2016. Social media and alcohol: Summary of research, intervention ideas and future study directions. Media and Communication 4(3): 50-59.

Pauley, P.M., \& Hesse, C. 2009. The effects of social support, depression, and stress on drinking behaviors in a college student sample. Journal of Communication Studies 60(5): 495-508.

Previte, J., Fry, M.L., Drennan, J. \& Hasan, S.F.E. 2015. Friends or foes: Group influence effects on moderate drinking behaviors. Journal of Business Research 68(10): 21462154.

Sornpaisarn, B., Kevin D. Shield, Esa Österberg, \& Jürgen Rehml. 2006. Thailand annual report on alcohol 2006. Bangkok: Center for Alcohol Studies.

Vanassche, S., An Katrien Sodermans, K. Matthijs, \& G. Swicegood. 2014. The effects of family type, family relationships and parental role models on delinquency and alcohol use among Flemish adolescents. Journal of Child and Family Studies 23: 128-143

World Health Organization (WHO). 2014. Global status report on alcohol and health 2014. Geneva: WHO.

Zhang, L., W. F. Wieczorek, \& J. W. Welte. 2012. The influence of parental and peer drinking behaviors on underage drinking and driving by young men. Journal of Drug Education 42(3): 347-359. 